\title{
On taxonomy of the Lispe caesia-group (Diptera: Muscidae)
}

\section{К систематике группы видов Lispe caesia (Diptera: Muscidae)}

\author{
Nikita E. Vikhrev ${ }^{1 *}$, Ying-Qiang $\mathrm{Ge}^{2}$, Dong Zhang ${ }^{2}$ \\ Никита Е. Вихрев ${ }^{1 *}$, Ин-Чан Гы ${ }^{2}$, Аон Ажканг ${ }^{2}$
}

\footnotetext{
${ }^{1}$ Zoological Museum of Moscow University, Bolshaya Nikitskaya 2, Moscow 125009, Russia.

1 Зоологический музей, МГУ им. М.В. Ломоносова, Большая Никитская ул. 2, Москва 125009, Россия.

2 School of Nature Conservation, Beijing Forestry University, Beijing 100083, China.

* Corresponding author. E-mail: nikita6510@ya.ru
}

KEY WORDS: Lispe caesia-group, Muscidae, Diptera. КЛЮЧЕВЫЕ СЛОВА: Lispe caesia-group, Muscidae, Diptera.

ABSTRACT. Two species of the Lispe caesia group were considered. A new synonym is proposed: $L$. caesia Meigen, 1826 = Lispe microchaeta Seguy, 1940, syn.n. L. odessae Becker, 1904 is re-established as a valid species. Distributional data on the considered species was substantially revised.

РЕЗЮМЕ. Рассмотрены 2 вида из группы видов Lispe caesia. Предложен новый синоним: L. caesia Meigen, 1826 = Lispe microchaeta Seguy, 1940, syn.n. L. odessae Becker, 1904 принимается в статусе валидного вида. Существенно уточнены и дополнены сведения о распространении рассмотренных видов.

\section{Introduction}

The Lispe caesia species-group was proposed by Hennig [1960] for five Palaearctic species: Lispe caesia Meigen, 1826; L. candicans Kowarz, 1892; L. halophora Becker, 1903; L. leucocephala Loew, 1856 and L. odessae Becker, 1904. According to Hennig [1960] these species share the following characters: frontal triangle broad, with convex margins; femora with ventral rows of short spines; abdomen with a characteristic pattern. Hennig [1960: 411] regarded the $L$. caesia group as "one of the most clearly defined», but the situation seems to be more complicated. Even among the species considered by Hennig [1960] L. leucocephala has neither ventral spines on femora nor abdominal pattern in both sexes. In the very recent review of the L caesia group [Zhang et al., 2016] the authors included in the group several more species. Intuitively we agree with addition of these species into the group, but formal characterization of the group as well as a revision of the abundant World fauna of the L. caesia group are the tasks for future. The present paper is restricted to correction of taxonomic confusions concerning only two species: L. caesia and the related $L$. odessae.

\section{Material and methods}

The specimens examined in this study are deposited in the following institutions:

JB - John Bratton's personal collection, Menai Bridge, $\mathrm{UK}$;

MBFU - Museum of Beijing Forestry University, Beijing, China;

MNHN — Muséum national d'Histoire naturelle, Paris, France;

NCU - Nicolaus Copernicus University, Torun, Poland;

TAUI - Tel-Aviv University, Israel;

ZIN - Zoological Institute, St. Petersburg, Russia;

ZMHU — Museum für Naturkunde, Humboldt-Universität zu Berlin, Germany;

ZMUM - Zoological Museum of Moscow University, Moscow, Russia.

Coordinates are given in the decimal degrees format.

The following generally accepted abbreviations for morphological structures are used: $f 1, t 1, f 2, t 2, f 3, t 3=$ fore-, mid-, hind- femur or tibia respectively; $a c$ acrostichal setae; $d c$ - dorsocentral setae; $a, p, d, v=$ anterior, posterior, dorsal, ventral seta(e).

The abbreviation for the tarsi as tar followed by a pair of digits separated by a hyphen was proposed by Vikhrev [2011]: the first digit (1 to 3) gives the leg number and the second digit (1 to 5) the number of the tarsal segment. For example, tar1-4 =4-th segment of fore tarsus; $\operatorname{tar} 3-1=$ hind basitarsus. cated.

The illustrations are original unless otherwise indi-

\section{Lispe caesia Meigen, 1826}

Figs 1-6.

Lispe caesia Meigen, 1826. Type locality: unknown.

Lispe microchaeta Séguy, 1940, syn.n. Type locality: Morocco, Rio de Oro. 
Lispe caesia microchaeta Séguy: Hennig, 1960.

TYPE MATERIAL. Holotype L. microchaeta, O (Figs 1-2): (Morocco), Rio de Oro prov., Villa Cisneros (= Dakhla, 23.69N 15.94W), Juin 1937, L. Berland (MNHN).

OTHER MATERIAL. [EGYPT], Port Said, 10 $0^{\top}, 1+$ (ZMHU)

ISRAEL, Ma'agan Michael $\left(32.56^{\circ} \mathrm{N} 34.91^{\circ} \mathrm{E}\right), 27.06 .1964$, A. Valdenberg, $100^{7} \sigma^{7}, 16$ 우 (TAUI)

[ITALY], Ven, P.Sabbioni, 8.05.1904, Gridelli, 10', 1 ( (ZMHU). [GERMANY, Lower Saxony state], Borkum (Isl., 53. $6^{\circ} \mathrm{N} 6.7^{\circ} \mathrm{E}$ ), 25.07.1901, W. Schnuse, $10^{7}, 1$ 우 (ZMHU).

MOROCCO: El Jadida prov., Oualidia lagune, $32.746^{\circ} \mathrm{N}$

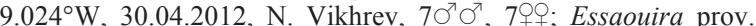
Essaouira env., $31.484^{\circ} \mathrm{N} 9.765^{\circ} \mathrm{W}, 1-5.05 .2012$, N.Vikhrev, $410^{7} \mathrm{O}^{7}$, 18우; Tan-Tan prov., salt lagune, $28.204^{\circ} \mathrm{N} 11.779^{\circ} \mathrm{W}$,

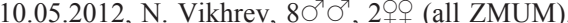

RUSSIA: Astrakhan reg., Baskunchak salt-lake, $48.19^{\circ} \mathrm{N}$ $46.82^{\circ} \mathrm{E}, 2-4.05 .2010$, K. Tomkovich, $10^{7}$; Kalmykia reg., Manych saltish L., $46.029^{\circ} \mathrm{N} 43.441^{\circ} \mathrm{E}, 9.06 .2012$, N. Vikhrev, $3 \mathrm{O}^{7} \mathrm{O}^{7}, 1$ 웅. Kurgan reg., Lebyazhye distr., $\left(55.08^{\circ} \mathrm{N} 66.91^{\circ} \mathrm{E}\right), 20.07 .2012$, V.

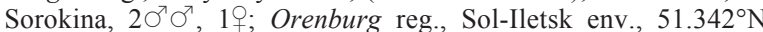

$55.013^{\circ} \mathrm{E}, 28.08$. K. Tomkovich, 2 oㅇ; Omsk reg., Omsk, Solenoe salt lake, $54.887^{\circ} \mathrm{N} 73.349^{\circ} \mathrm{E}, 24.07 .2012$, O. Kosterin, $6 \mathrm{O}^{\top} \mathrm{O}^{\top}, 1$; Volgograd reg., salt pool, $48.465^{\circ} \mathrm{N} 44.570^{\circ} \mathrm{E}, 8.06 .2012$, N. Vikhrev, $20^{7} 0^{7}, 1$ (인 (all ZMUM).

UKRAINE, Odessa reg., Odessa env., Kuaylnik $\left(46.57^{\circ} \mathrm{N}\right.$ 30.74 ${ }^{\circ}$ E), 14-16.09.1938, B. Rohdendorf, $30 \mathrm{O}^{7} \mathrm{O}^{7}+0$ (ZMUM).

TURKEY: Adana prov., seashore salt marsh, $36.74^{\circ} \mathrm{N} 35.62^{\circ} \mathrm{E}$, 12.04.2010, N. Vikhrev, $70^{\top} 0^{7}+9$ (ZMUM); Ankara prov, Tuz Lake, $38.78^{\circ} \mathrm{N} 33.63^{\circ} \mathrm{E}, 20.04 .2010$, N. Vikhrev, $11 \sigma^{7} \mathrm{O}^{7} \mathrm{O}$. (ZMUM); Hatay prov., Samandag env., salt lake, $36.074^{\circ} \mathrm{N} 35.953^{\circ} \mathrm{E}$, 16.04.2010, N. Vikhrev, 10, 2우 (ZMUM); Mersin prov., seashore salt marsh, $36.31^{\circ} \mathrm{N} 34.01^{\circ} \mathrm{E}, 22.04 .2010$, N. Vikhrev, $230^{7} \mathrm{O}^{7} \mathrm{O} O \mathrm{O}$ (ZMUM); Mugla prov., Iztuzu beach $\left(36.80^{\circ} \mathrm{N} 28.61^{\circ} \mathrm{E}\right), 9-$ 17.06.2010, A. Grzywacz, $5 \mathrm{O}^{7} \mathrm{O}^{7}, 6$ 우 (NCU).

UK, N Wales, Isle of Anglesey, Cymyran, sandy saltmarsh, $53.25^{\circ} \mathrm{N} 4.55^{\circ} \mathrm{W}, 7.09 .2006$, J. Bratton, $10^{7}, 1$ ( $(\mathrm{JB})$

DISTRIBUTION. Was known from Europe, N Africa and Near East. Material listed above shows that L. caesia is also widely distributed in SE of European Russia and W

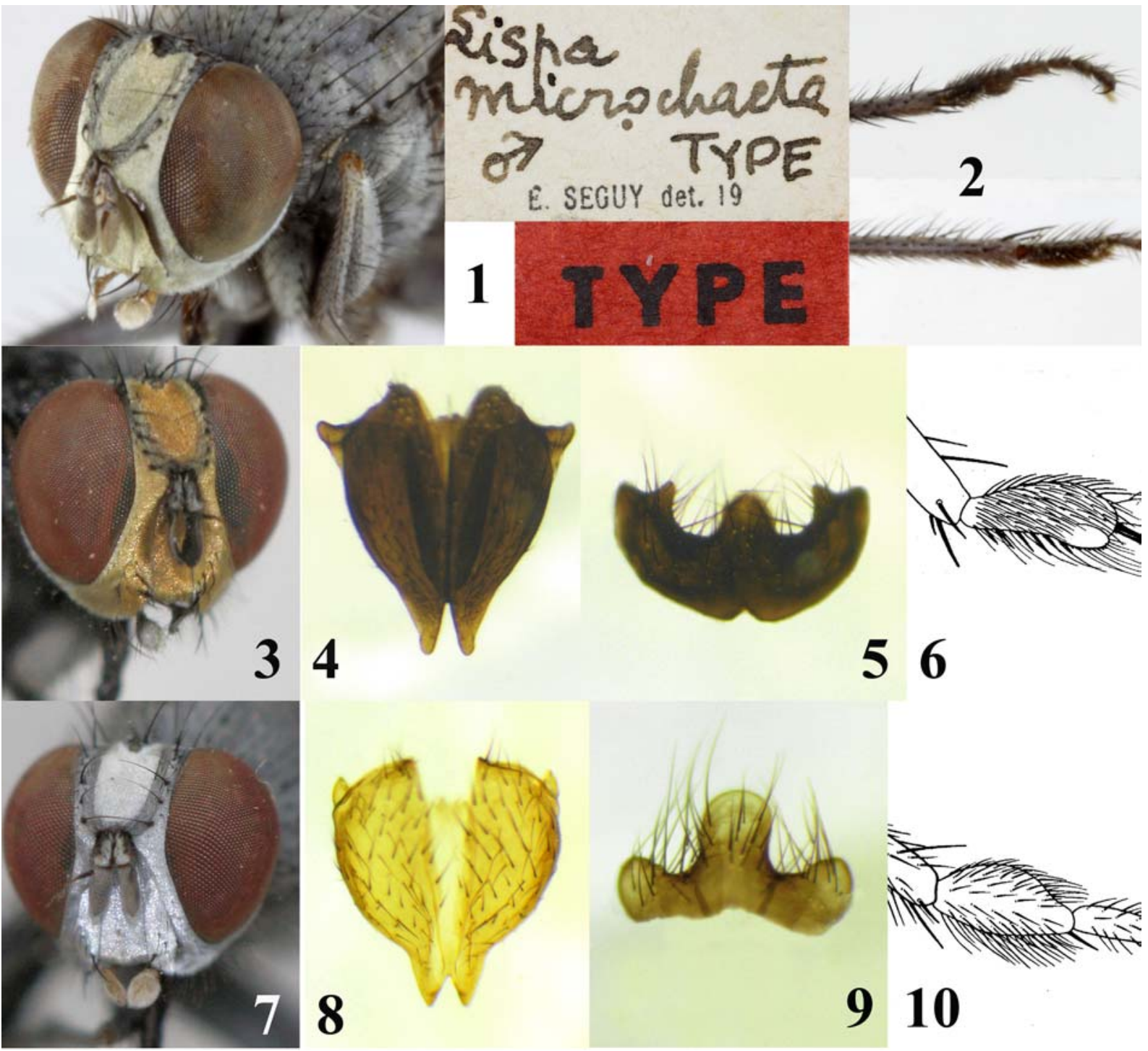

Figs 1-10. Lispe spp., $0^{7} \bigcirc^{7}: 1-2-$ L. microchaeta, Holotype; 3-6 - L. caesia; 7-10 - Lispe odessae; 1, 3, 7 - head; 2 - tar3-1 from different points of view; 4, 8 - cercal plate; 5, 9 - sternite 5; 6, 10 - tar3-1 [after Hennig, 1960: 404: textfigg 100 and 98].

Рис 1-10. Lispe spp., о о $0^{7}$ : 1-2 - L. microchaeta, голотип ; 3-6 - L. caesia; 7-10 - Lispe odessae; 1, 3, 7 - голова; 2 - tar31 с разных сторон; 4, 8- церки; 5, 9 - стернит 5; 6, 10 - tar3-1 [по Hennig, 1960: 404: textfigg 100 and 98]. 
Siberia, though is rather uncommon in the north-eastern part of the natural habitat.

SYNONYMY. In the original description Séguy [1940] compared L. microchaeta with L. pygmaea Fallén, 1825 and $L$. flavicincta Loew, 1847, both having nothing to do with $L$. microchaeta. Hennig [1960] reexamined the type material and found the true identity of this species: L. microchaeta is $L$. caesia with yellow palpi instead of the typical blackish ones. We also reexamined the holotype of $L$. microchaeta and came to the same conclusion. The characteristic modification of male tar3-1 (Figs 2,6) makes L. caesia unmistakable. Hennig [1960] regarded the considered taxon as a yellow-palpish subspecies $L$. caesia microchaeta, while we offer here a more radical point of view that the species is monotypical. The dusting of frontal triangle, face and palpi widely vary in $L$. caesia: the frontal triangle and face vary from deep yellow (as on Fig. 3) to yellowish-white (Fig. 1); the palpi could be almost black (Fig. 3) or dirty-yellow with darkened apex or rarely almost pure yellow (Fig.1). We have seen specimens of $L$. caesia with yellow palpi from Morocco, Russia (W Siberia, Omsk reg.) and UK. We regard Lispe caesia Meigen, 1826 = Lispe microchaeta Séguy, 1940: 342, syn.n.

\section{Lispe odessae Becker, 1904 \\ Figs 7-10}

Lispe odessae Becker, 1904. Type locality: Ukraine, Odessa. Lispe odessae Becker, 1904: Hennig, 1960.

Lispe caesia Meigen, 1826: Canzoneri \& Meneghini, 1966.

Lispe caesia Meigen, 1826: Pont, 1986.

Lispe caesia microchaeta Séguy, 1940: Zhang et al., 2016.

TYPE MATERIAL. Holotype, $\sigma^{7}$ : Odessa, 50437, IX (Becker notebooks: 1 ex., 8.ix.1903, "am Ufer Salzsees" (= on the banks of Salt Lake in German) "Liman" (= estuary, in Russian) = Ukraine, Odessa, 46.5N 30.7E, coastal salt lake bank, 8.09.1903 (ZMHU).

OTHER MATERIAL. CHINA: Liaoning prov., Jinzhou City, Longqi Bay, 40.87N 121.25E, 8-12.08.2014, Xinyu Li, 7 $\Im^{7} \sigma^{7}$, 15 우 (MBFU); Xinjiang prov., Kalamaili_Nature_Reserve, 45.1N 88.9E: 14-16.08.2009, Dong Zhang, $3 \sigma^{\top} \sigma^{\top}, 7$ 7 $9+\%$; 26.05 .2014 , Dong

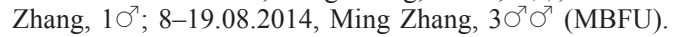

KAZAKHSTAN: Kyzylorda reg., Aralsk, salt lake, 46.79N 61.67E, 12.05.2011, K. Tomkovich, 1+; W. Kazakhstan prov., Shalkar L., $50.58^{\circ} \mathrm{N} 51.79^{\circ} \mathrm{E}, 27.08 .2012$, K. Tomkovich, $10^{7}$ (all ZMUM)

MONGOLIA, Yuzhno-Gobiyskiy aimak (Omnogovi prov.): 40 $\mathrm{km} \mathrm{SSE}$ of Nomgon $\left(42.45^{\circ} \mathrm{N} 105.25^{\circ} \mathrm{E}\right)$, V. Zaitsev, 9.08.1967, 1 \% $10 \mathrm{~km} \mathrm{NE}$ of Onch-Khairkhan-Ula Mt. $\left(42.16^{\circ} \mathrm{N} 104.93^{\circ} \mathrm{E}\right), \mathrm{V}$. Zaitsev, 9.04.1967, $10^{7}$ (ZIN).

RUSSIA: Astrakhan reg., Baskunchak salt-lake, $48.19^{\circ} \mathrm{N}$ 46.82 ${ }^{\circ}$ E, 2-4.05.2010, K. Tomkovich, $20 \bigcirc^{7} \bigcirc^{\top}$, 9우; Kalmykia reg. Elista env., $46.213^{\circ} \mathrm{N} 43.956^{\circ} \mathrm{E}, 9.06 .2012$, N. Vikhrev, 1 웅, Priyut-

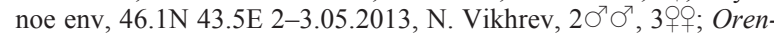
burg reg., Sol-Iletsk env., $51.342^{\circ} \mathrm{N} 55.013^{\circ} \mathrm{E}, 28.08 .2012$, K. Tomkovich, 3 O+o; Volgograd reg., salt pool, $48.465^{\circ} \mathrm{N} 44.570^{\circ} \mathrm{E}$, 8.06.2012, N. Vikhrev, $10^{7}$ (all ZMUM).

TURKMENISTAN, Mary reg., Bathyz NR, $\approx 37^{\circ} \mathrm{N} 62^{\circ} \mathrm{E}$, 25.05.1991, A. Ozerov, $10^{7}, 2$ 우 (ZMUM).

DISTRIBUTION. Inland salt basins and estuaries at sea shore. Palaearctic, from E Europe to Asian Far East. Hereby newly recorded for China, Kazakhstan, Mongolia, Russia and Turkmenistan.

DISCUSSION. For a long time L. odessae was known by the male holotype only. Hennig [1960] examined the holotype, made redescription of $L$. odessae and gave recommendation how to distinguish this species from L. caesia. We also examined the holotype and 80 freshly collected specimens of L. odessae (see above). We came to the same conclusion as Hennig: it is a valid and good species which differs from the related $L$. caesia as follows:

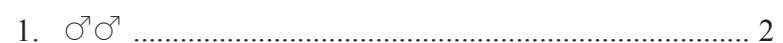

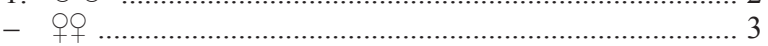

2. $t 3$ on $a v$-surface with a complete row of fine elongated setulae, without strong setae. $t 2$ with ad seta about 2 times shorter than $p d$ seta. tar3-1 diamond-shaped as on Fig. 10. Frontal triangle and face silvery-white dusted, without yellowish tint (Fig. 7). Palpi yellow (Fig. 7). Sternite 5 with long median process; short and rounded lateral processes as on Fig. 9. Cercal plate similar to that of $L$. caesia, but more roundish shaped and with shorter apical prongs (Fig. 8). odessae Becker - $t 3$ on $a v$-surface without fine elongated setulae, but with 2 (1-3) strong setae in apical 1/3.t2 with ad seta as long or longer than $p d$ seta. tar3-1 with ventral rounded process in apical half as on Figs 2 and 6. Frontal triangle and face yellow-white (Fig. 1) to deep yellow (Fig. 3) dusted. Palpi blackish (Fig. 3) or dirty-yellow with blackish apex, rarely yellow (Fig. 1). Sternite 5 with short median process; lateral processes longer and bifurcated at apices as on Fig. 5. Cercal plate similar to that of $L$. odessae, but narrower and with longer apical prongs (Fig. 4). ........ caesia Meigen 3. $f 3$ with preapical $a v$. Palpi yellow. Body length 5-7 mm. odessae Becker

- $f 3$ without preapical $a v$. Palpi blackish or blackish at apex or dirty yellowish, rarely yellow. Body length 6.5$8 \mathrm{~mm}$. caesia Meigen

Canzoneri and Meneghini [1966] synonymized L. odessae with L. caesia. Based on this synonymy and the absence of any formal refutation of it, Pont [1986] listed in the Palaearctic Catalogue $L$. odessae as a synonym of $L$. caesia. Since that, this point of view became generally accepted and was also used in Zhang et al. [2016] review of the Lispe caesia group. Presently we would like to refute it. As translated from Italian to English, Canzoneri and Meneghini [1966] reasons were as follows: «we recently examined a specimen of $L$. odessae from Denmark, Museum of Copenhagen: it perfectly fits the description given by Hennig for L. odessae. However, the genitalia and the leg chaetotaxy are indistinguishable from those of L. caesia.» Firstly, either the specimen perfectly fits $L$. odessae or it has characters of $L$. caesia. Secondly, if some specimen looks as L. caesia, has the genitalia, tibial chaetotaxy and tar3-1 modification as in L. caesia, than indeed L. caesia it is. Even in the field practice L. odessae differs from $L$. caesia not only by smaller size and bright silvery frons, but also being faster and more cautious species than L. caesia.

Through the above discussed erroneous view on L. odessae as a synonym, this species was misidentified as $L$. caesia microchaeta in the recent publication on the Lispe caesia species group [Zhang et al., 2016]. Thus, L. odessae is a species hereby newly recorded for China as well as for Kazakhstan, Mongolia, Russia and Turkmenistan.

ACKNOWLEDGEMENTS. We thank Joachim Ziegler and Jenny Polh (Berlin), Christophe Daugeron and Emmanuel Delfosse (Paris), Olga Ovchinnikova, Galina Suleymanova and Ludmila Kuznetsova (St. Petersburg), Amnon Freidberg (Tel-Aviv), John Bratton (Menai Bridge, UK), Andrzej Grzywacz, (Torun, Poland) for the kind possibility to examine their important material. We thank Oleg Kosterin (Novosibirsk) for his advices and corrections.

This study was supported by the Fundamental Research Funds for the Central Universities (No. JC2015-04), and the National Science Foundation of China (No. 31201741). 


\section{References}

Canzoneri S., Meneghini D. 1966. Lispe Latr. del Mediterraneo e Medio Oriente raccolte da A. Giordani Soika // Bollettino del Museo Civico di Storia Naturali di Venezia, Vol.16. P.109-148. Hennig W. 1960. Family Muscidae (Lieferung 209 and 213) // Lindner E. (Hrsg.). Die Fliegen der Palaarktischen Region. Schweizerbart, Stuttgart. Bd.63b. S.385-480.

Pont A.C. 1986. Family Muscidae // Soós A., Papp L. (eds.) Catalogue of Palaearctic Diptera. Vol.11. Budapest: Akadémia Kiadó. P.57-215.
Séguy E. 1940. Recoltes entomologiques de M. L. Berland a Villa Cisneros (Rio de Oro). Insectes Dipteres // Bulletin du Muséum National d'Histoire Naturelle. Paris. Vol.2. No.12. P.340343.

Vikhrev N. 2011. Review of the Palaearctic members of the Lispe tentaculata species-group (Diptera, Muscidae): revised key, synonymy and notes on ecology // ZooKeys. Vol.84. P.59-70.

Zhang D., Ge Y-Q., Li X-Y., Li X-H., Zhang M., Wan R-R. 2016. Review of the Lispe caesia-group (Diptera: Muscidae) from Palaearctic and adjacent regions, with redescriptions and one new synonymy // Zootaxa. Vol.4098. No.1. P.043-072. 